Research Report

\title{
The African Trading Community in Guangzhou: An Emerging Bridge for Africa-China Relations*
}

\author{
Adams Bodomo ${ }^{\dagger}$
}

\begin{abstract}
This article analyses an emerging African trading community in Guangzhou, China. It is argued that migrant communities such as this one act as linguistic, cultural and economic bridges between their source communities and their host communities, even in the midst of tensions created by incidents such as immigration restrictions and irregularities. Sociolinguistic and socio-cultural profiles of this community are built, through questionnaire surveys and interviews, to address issues such as why Africans go to Guangzhou, which African countries are represented, what languages are spoken there, how communication takes place between Africans and Chinese, what socio-economic contributions Africans in Guangzhou are making to the Chinese economy, and how the state reacts to this African presence. Following from the argument that this community acts as a bridge for Africa-China relations it is suggested that both the Chinese and the African governments should work towards eliminating the harassment of members in this community by many Guangzhou law enforcement officials and instead harness the contributions of this community to promote Africa-China socio-economic relations.
\end{abstract}

Fifty years after the Bandung conference in April 1955 officially marked the beginning of Afro-Asian relations, we are beginning to see the establishment of African communities in Asia, especially in megacities such as Beijing, Tokyo, Seoul and Mumbai. In China, besides Beijing, African communities have become a reality in cities such as Shanghai and Hong Kong. ${ }^{1}$ There are now more

\footnotetext{
* I thank the HKU Research Grants Committee for funding my research project "The African Diaspora in China: the case of Hong Kong and Guangzhou" (project no. 10207573), through which research for this article was undertaken. I also thank audiences at the SOAS China-Africa workshop in London (September 2008) and the Chinese Society for the Study of Africa's Africa-China conference at Shanxi University in Taiyuan (October 2008) where earlier versions were read. I am grateful to Frances Lung, Yeung Hui Lam and Iris Yu for helping me in the field and for other research assistance.

$\dagger$ The University of Hong Kong. Email: abbodomo@hku.hk

1 Brigitte Bertoncello and Sylvie Bredeloup, “The emergence of new African 'trading posts' in Hong

C) The China Quarterly, 2010 doi:10.1017/S0305741010000664
} 
Africans and people of African descent in southern Chinese cities such as Hong Kong, Macau and particularly Guangzhou than in any other part of China. ${ }^{2}$

Given the current rate and dynamics of the establishment of communities in China by Africans and people of African descent it is not far-fetched to foresee that in 100 years' time an African-Chinese Minority Ethnic Group could be demanding self-identity and full citizenship rights in the heart of Guangzhou and other major cities. Questions would then be raised about who the ancestors of these ethnic minorities were, where they came from and what for, what were their linguistic and cultural backgrounds, what contributions they have made to the Chinese nation, and what challenges they face with regard to relations with their hosts.

This article proposes some answers to these questions by focusing on the emergence of an African trading community in Guangzhou, capital of Guangdong province and the largest city in southern China. Based on a questionnaire survey, in-depth interviews and community interactions, it constructs a profile of this community, showing the enormous contributions Africans are making, but also the challenges they face. It then argues that one of the best ways to promote Africa-China relations is to recognize the important contributions made by Africans in China, minimize their challenges, promote their welfare, and make them act as important bridges in the process of Africa-China socio-economic integration.

The article begins by presenting background surveys of literature and a theoretical construct to anchor the idea of using the African community (or the various national communities) in Guangzhou as a bridge (or bridges) for African-Chinese relations. The next section outlines the methodology used in the field to collect, collate and analyse the research data. Then, using this data, I build socio-linguistic and socio-cultural profiles of the African community in Guangzhou, along with an outline of its socio-economic role. These profiles provide useful findings about the target community, helping to answer or at least address most of the questions posed. Based on these findings, I argue that the study of this community sheds new light on the role of migrant communities in the 21st century: they can act as bridges for linguistic, cultural and economic contact and integration between the source and host communities. This theoretical construct can be the basis for studying other migrant communities.

\footnotetext{
footnote continued

Kong and Guangzhou," China Perspectives, No. 1 (2007), pp. 94-105; Adams Bodomo, "An emerging African-Chinese community in Hong Kong: the case of Tsim Sha Tsui's Chungking Mansions," in Kwesi Kwaa Prah (ed.), Afro-Chinese Relations: Past, Present and Future (Cape Town: The Centre for Advanced Studies in African Societies, 2007) pp. 367-89.

2 Bodomo, "An emerging African-Chinese community in Hong Kong"; Adams Bodomo, "The emergence of African communities in Hong Kong and mainland China," paper for Africa Table, Stanford University African Studies Centre, 23 May 2007; Li Zhigang, Xue Desheng, Michael Lyons and Alison Brown, "The African enclave of Guangzhou: a case study of Xiaobeilu," Geographica Sinica, Vol. 63, No. 2 (2008).
} 


\section{Literature Review, Theoretical Construct and Background of Research Location}

While the Tianxiu 天秀 building and the general Xiaobeilu 小北路 area have been the subject of newspaper and magazine reports in Chinese and European polities, only a few academic research studies have been dedicated to this emerging African community. ${ }^{3}$ However, what is happening in Guangzhou is of relevance to studies on immigrant communities in Asia and other parts of the world. ${ }^{4}$

One common theme of most of the earlier studies on modern African communities in China is an emphasis on the novelty of the situation. While it is true that there have been Africans in China, including students and diplomats, for a long time, there has never been, until now, a massive presence of Africans from all walks of life actually migrating to China to start up businesses serving both Africans and Chinese.

\section{The "immigrant community as bridge" theory}

In this article, I propose a "bridge" theory for describing the role of this emergent migrant community. In straightforward terms, this theory claims the following: Africans resident in Guangzhou, through their activities either intentionally or unintentionally, serve as linguistic, cultural and business links and connections between their Chinese hosts and Africans in their home countries as well as those who arrive newly in China. In other words, Chinese in Guangzhou perceive African culture and business practices in the first instance through these Africans who live among them, and Africans in Africa and those who newly arrive in Guangzhou can perceive Chinese culture and ways of doing business through the Africans resident in Guangzhou. With evidence from a questionnaire survey and interviews with community members I illustrate and demonstrate this thesis, thus projecting this community as acting as a bridge for stronger Africa-China relations. Of course, the idea of a bridge theory is not new in the literature on migration. There is much work on migrant communities serving as bridges between their host and home communities, such as Evelyn Kallen's study of

3 See e.g. Bodomo, "An emerging African-Chinese community in Hong Kong," pp. 367-89; Bodomo, "The emergence of African communities in Hong Kong and mainland China"; Brigitte and Bredeloup, "The emergence of new African "trading posts"; Li et al., "The African enclave of Guangzhou."

4 See e.g. Bok Rae Kim, "The African presence in Korea," in Kiran Kamal Prasad and Jean-Pierre Angenot (eds.), The African Diaspora in Asia, Explorations on a Less Known Fact: Papers Presented at the First International Conference on the African Diaspora in Asia in Panaji, Goa (2008) pp. 43644; Paul Stoller, Money Has No Smell: The Africanization of New York City (Chicago: Chicago University Press, 2001); Janet MacGaffey and Remy Bazenguissa-Ganga, Cong-Paris: Transnational Traders on the Margins of the Law (Indiana: Indiana University Press, 2000); Joseph McIntyre, Wurzel in zwei Welten: westafrikanische Migranten und Migrantinnen in Hamburg (Frankfurt am Main: Brandes und Apsel, 2004); Bonnie Urciuoli, Exposing Prejudice: Puerto Rican Experiences of Language, Race and Class (Boulder: Westview Press, 1996). 
Western Samoan migrants in New Zealand. ${ }^{5}$ But some scholars do not see migrant communities in this light.

Are there therefore any alternatives to the bridge theory, especially with respect to Africans in Guangzhou, from the small number of studies so far on this community? While not explicitly denying that it acts as a bridge between Chinese in China and Africans in Africa, Li Zhigang et al. describe it as an "enclave" 6 while Bertoncello and Bredeloup see it as an "outpost" in isolation from the rest of the larger host community. ${ }^{7}$ It may be argued that seeing the community as an outpost or an enclave is a potential alternative to seeing it as a bridge between its host Chinese community and its home or source African community.

The position in this article is that, while this community may have elements of enclosure and isolationism with regards to its host community, it can, and indeed does, serve as a link connecting its place of origin, its source community, with its place of domicile, its host community. We argue for this theory based on evidence from investigations into the core centre of the African community in Guangzhou. While a community can never fully be an enclave and isolated from its host community nor ever fully integrate into this community, given the right conditions it can always serve as a bridge between its source and its host community. This theory of the migrant community as a bridge can be very amenable to dealing with issues in the emergent fields of contact linguistics and cross-cultural or urban anthropology, among other areas of study. For instance, in practical terms, the bridge theory would imply the migrant community attempting, even in the face of harsh immigration rule enforcements by the Guangzhou authorities, to negotiate harmonious and generally beneficial relationships between themselves, their host community and their source community. This can be seen in Guangzhou where there are brisk business and other largely peaceful interactions between ordinary Africans and ordinary Chinese people.

But there are other examples in the social and cultural anthropology literature, such as Jeffrey Cole's account of African migration in Italy and Europe as a whole, focusing not on the migrant group but on the host community's not so peaceful and positive reaction to the migrants, which show that the relationship can be anything but harmonious and beneficial. ${ }^{8}$ Indeed, in recent times there have been incidents, such as the one reported in Hong Kong's South China Morning Post on 16 July 2009, ${ }^{9}$ of conflict between the Africans and Guangzhou law enforcement

5 Evelyn Kallen, The Western Samoan Kinship Bridge: a Study in Migration, Social Change, and the New Ethnicity (Leiden: Brill, 1982).

6 Li et al., "The African enclave of Guangzhou."

7 Brigitte and Bredeloup, "The emergence of new African 'trading posts'."

8 Jeffrey Cole, The New Racism in Europe: A Sicilian Ethnography (Cambridge: Cambridge University Press, 2005).

9 In its 16 July 2009 edition the SCMP splashed the following sensational headline on its front page: "Africans protest in Guangzhou after Nigerian feared killed fleeing visa check," with a large picture of black people protesting in Guangzhou, some holding bloodied shirts to onlookers. The SCMP is Hong Kong's main English-language journal read mainly by Western expatriates in Hong Kong, and this sensational reporting really caused a stir in Hong Kong and southern China. Ordinary people suddenly woke up to the presence of a large community of Africans in Guangzhou, with the uncomfortable 
authorities that seem to contradict the idea of a harmonious reaction to the immigrants.

However, I argue that this incident and other similar ones do not negate the bridge theory advanced here. There are two main reasons in support of this. First, the July 2009 incident in Guangzhou did not involve a clash between Africans in Guangzhou and their host Chinese population en masse. It simply involved the police on a periodic raid for illegal immigrants. One illegal African immigrant was cornered and decided to escape by jumping from his second-floor apartment to the ground, in the process fatally injuring himself. African community members reacted very angrily, and since then tension, unease and even fear have increased in the community, creating not so cordial relations between the law enforcement authorities and many Africans resident in Guangzhou. Reports coming out of Guangzhou, especially by Western newspapers, created the impression that suddenly ordinary Chinese and Africans were at each others' throats, but this is far from the truth.

It is even tempting to compare this incident with what happened in 1988 in Nanjing when mostly Chinese students clashed with African students. ${ }^{10}$ This would however be an error, since what happened then was a clash between ordinary Chinese people and ordinary African students, on the eve of the 1989 Tiananmen incident in Beijing during a time when there was general discontent among some segments of the Chinese student population with the then authorities. It could be seen as an act of nationalism, since the students saw the authorities of the time to be aligning with "backward third world people" as claimed by Sullivan. ${ }^{11}$ What is happening now in Guangzhou and other Chinese cities is clashes between mostly illegal African residents and harsh, draconian and largely corrupt law enforcement authorities, not community clashes between the African migrant communities and the Chinese communities.

The second point in support of the argument that tensions created by law enforcement officers maltreating Africans do not negate the bridge thesis, is the fact - supported by the questionnaire survey, interviews and observation of this community - that there are still booming business and personal relations between Africans and Chinese in Guangzhou, with each positively influencing the other culturally. For instance, of late Chinese people have started learning how to make African food and even sell it back to Africans. Not only are Africans getting more proficient in Chinese languages and cultures, but many of the Chinese traders interviewed in Tianxiu and Canaan markets are learning

\footnotetext{
footnote continued

effect that every African in Hong Kong and southern China was perceived as a potential illegal immigrant.

10 Michael Sullivan, "The 1988-89 Nanjing anti-African protests: racial nationalism or national racism?" The China Quarterly, No 138 (1994), pp. 438-57.

11 Ibid.
} 
to speak a form of English that is recognizably African English. Hence, in many ways, the bridge theory of cultural influences and exchange between Africans and Chinese in Guangzhou markets is not negated by recent incidents involving clashes between assumed illegal African immigrants and law enforcement officers.

\section{Guangzhou's "chocolate city”}

Guangzhou is one of the biggest cities in China, attracting many businessmen from different parts of China. For many reasons, Guangzhou also attracts many African businessmen. ${ }^{12}$ For one thing, it is situated in Guangdong, the Chinese province with the largest manufacturing base for the kind of goods that Africans need to ship back to Africa. This study focuses on the African community at the Tianxiu building and other nearby buildings and markets and explores the linguistic contact and cultural relationships between Africa and China. This part of Guangzhou has been nicknamed "chocolate city" in reference to the many Africans (whose skins are dark or brown) living in the area. ${ }^{13}$ My questionnaire survey was conducted mainly in two areas, the Tianxiu building in Xiaobei district (located at No. 300 Huanshizhong 环市中 Road, and the Canaan Export Clothes Wholesale Trade Centre, including two Tian'en 天恩 export trade buildings at Guangyuan xi 广园西 Road.

\section{Methodology}

To address the main aim of this study - to answer questions such as who these Africans are, where they come from, why they come to Guangzhou, how communication takes place, how the communities are organized and how they contribute to the economy of their adopted country of residence - I did an empirically based socio-linguistic and urban anthropological survey of the area of Guangzhou dubbed "chocolate city." This kind of survey is appropriate for teasing out issues within the growing disciplines of contact linguistics and crosscultural studies.

The study began with preliminary visits in July 2006 to identify field locations and significant players in the community, enabling the questionnaire to be drafted. This was followed by a pilot survey in December 2006 where the questionnaire was administered and a report produced, which led to correction and fine-tuning of a number of issues and the creation of a new questionnaire. ${ }^{14}$

The main survey reported in this article was conducted over a week, from 25 to 30 May 2008 , by the author and two research assistants. About 100

12 Li et al., "The African enclave of Guangzhou."

13 The South Metropolis Daily in its January 2008 edition wrote: "Due to the skin color of black or brown of Africans here, the region is called 'Chocolate City' by Guangzhou people."

14 Bodomo, "The emergence of African communities in Hong Kong and mainland China." 
questionnaires were given out, of which 77 valid ones were returned, and eight community members including some community leaders were interviewed in depth.

The questionnaires aimed at identifying participants in terms of places and countries of origin, gender, age, sociolinguistic profile, such as what languages they speak in different places along with their communication patterns, and socio-cultural profile, like how closely connected they are to their host community. The questions in the main followed an earlier survey of the Chungking 重 庆 Mansions African community in Hong Kong. ${ }^{15}$ The data obtained, complemented by information from the interviews with community members, were compiled into detailed statistical reports. The following section attempts a profile of the community in a bid to gain insights into its core structure.

\section{Analysis: Profiles of Guangzhou's "Chocolate City"}

\section{Demographics}

The profiles comprise age, gender, nationality and profession, but here statistics are only given about occupation and nationality. ${ }^{16}$

Do Africans in Guangzhou only serve as traders, dealing mainly in retail and the import-export business or they are involved in other occupations? Our statistics, as shown in Figure 1, indicate that although an overwhelming number, almost 95 per cent, report their occupations as "businessmen" or "traders" the remaining 5 per cent report other occupations such as "artist" and "housewife." This is not surprising, because as the community establishes itself people of African origin will begin catering to the community as artists (usually musicians) footballers, barbers and cooks, among others. Indeed, there is now an increasing number of barber shops and hairdressing salons catering to African hairstyles in "chocolate city." In addition, many African restaurants are springing up in and around the Tianxiu building.

An often asked question about the African population of more than 100,000 people in the heart of Guangzhou is what African countries are represented. Our research results show that out of 77 random respondents, 33 are Nigerians (the largest group), ten are Malians, eight are Ghanaians and six are Guineans; the remaining respondents are of a variety of nationalities, as shown in Figure 2. As can be seen, an overwhelming majority of the community members are from West African countries. The main reason for this is likely to be that Nigeria is the most populous country in Africa with more than 120 million people, far larger than most country populations in Southern, Eastern and

15 Bodomo, “An emerging African-Chinese community in Hong Kong," pp. 367-89.

16 Age-wise, these are people mostly in their $20 \mathrm{~s}$ and $30 \mathrm{~s}$; in terms of gender there are more men than women; and in terms of schooling, many of them have finished high school and some even have tertiary education. 
Figure 1: The Occupations of the Respondents

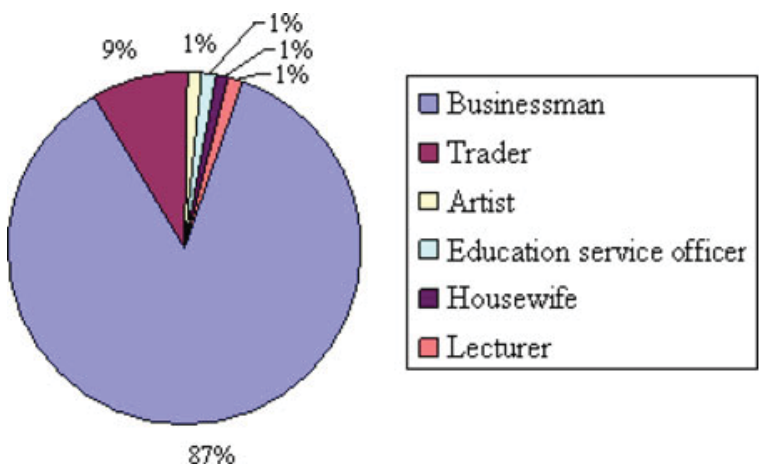

Figure 2: The Nationality of the Respondents

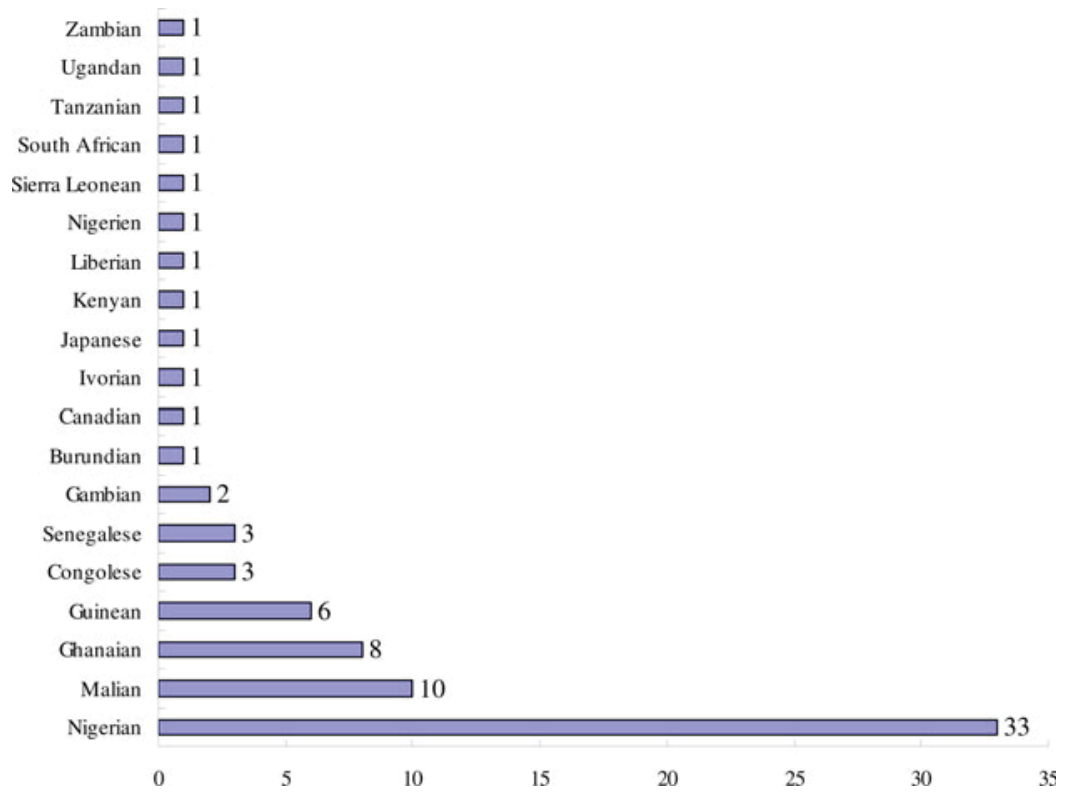

Northern Africa. It is therefore not surprising that Nigerians - and thus West Africans - are more represented. ${ }^{17}$

Contact linguistics: a sociolinguistic profile of "chocolate city"

The African community in Guangzhou constitutes an interesting experiment in cross-linguistic communication and therefore merits the attention of contact

17 For other reasons for this West African preponderance, especially with Ghanaians, Guineans and Malians, see Bodomo, Africans in China, book manuscript in preparation. 
linguists and other cross-cultural communication experts. ${ }^{18}$ English is the main lingua franca in the community for interaction with non-Africans, along with Chinese and French. Many native African languages like Igbo, Bambara, Lingala, Twi and Swahili can already be heard in the shopping centres and churches of Guangzhou. There are several problems of communication in all this complexity.

Since a great number of languages are spoken and Guangzhou people do not generally have high levels of proficiency in English, the questionnaire asked how often people encountered communication problems. Some 50 per cent of the respondents claimed that they never or seldom came across communication problems, while 50 per cent claimed that they sometimes, often or always had such kinds of problems, as shown in Figure 3. Though these statistics suggest that half of the population does not experience communication problems, in-depth interviews clearly indicated that they do, and observation of Africans buying goods from Chinese stores confirmed this. How then are these communication problems negotiated? Two main strategies are hiring a bilingual secretary or using calculators as described below.

Many Africans in Guangzhou often joke that even though they don't speak Chinese they have no communication problems when trading with Chinese people because they can communicate through their calculators in combination with basic body gestures. This mainly non-verbal communication event of establishing prices and buying begins with the African buyer pointing to the goods and asking the price through a combination of hand gestures and basic English or French sentences, like "how much?" or "combien?" The Chinese seller responds by typing in the price on a calculator and showing it to the African, who replies by a shake of the head, usually in disagreement to start with, since in most African cultures every price in the market place is subject to negotiation. The African buyer then types in a suggested price on another calculator and shows it to the Chinese trader. The Chinese responds to this offer with gestures accompanied by basic Chinese phrases like "bu shi" (不是, not right) or “hao de" (好的, sounds good). This process continues until buyer and seller agree or disagree on a price and the sale deal is either closed or aborted. Price bargaining in a market situation is a salient African cultural practice and the Chinese traders have learned this very fast and practise it to perfection by a combination of "calculator communication," body language and basic Chinese and English expressions.

\section{Socio-cultural identities}

Is there a process of acculturation into Chinese society? Do Africans interact culturally with Chinese (beyond trade) or do they basically keep within their own cultural habits? To illustrate and answer this, the questionnaire asked various questions about food consumption. ${ }^{19}$

18 Ibid.

19 Other activities such as festivals, dancing and worship are discussed in ibid. 
Figure 3: How Often Do You Come Across Communication Problems at the $\mathrm{X}$ Building?

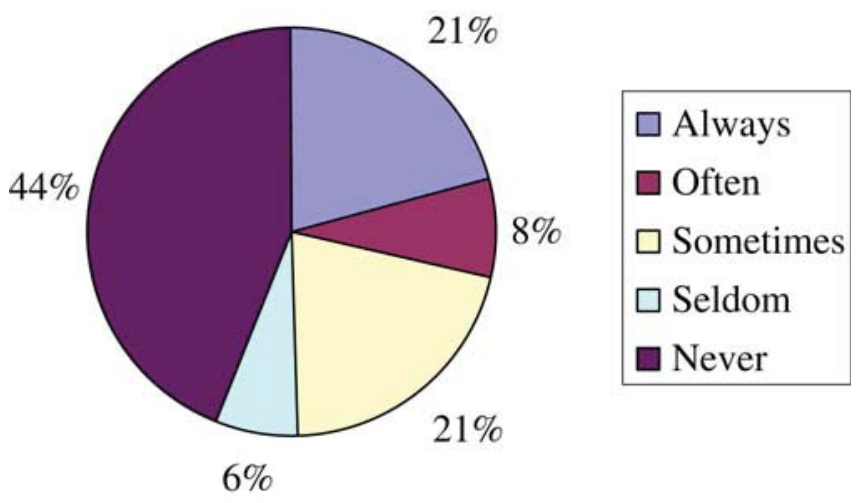

Issues of food constitute an important aspect of a community's socio-cultural profile. Some survey questions were therefore primarily concerned about the diet and eating habits of the respondents to determine how much African food was still eaten and whether any acculturation processes were in progress in terms of consumption of Chinese food. We asked respondents how often they consumed Chinese food, to reflect the acceptability of Chinese food to them. The results indicated that 21 per cent of respondents would always or often consume Chinese food, while 61 per cent would sometimes do so. However, 18 per cent seldom or never consumed any Chinese food. Details are shown in Figure 4.

Similar questions about the consumption of African food revealed that 54 per cent of respondents would always or often eat food from their countries of origin, while 40 per cent would sometimes do so. Six per cent of the respondents seldom or never eat food from their countries of origin (see Figure 5).

Figure 4: How Often Do You Eat Chinese Food?

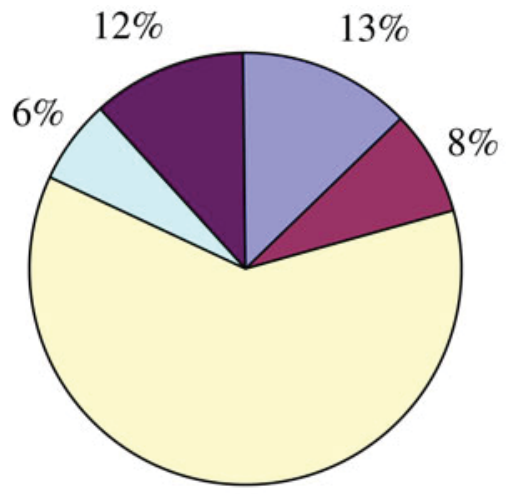

$\square$ Always
$\square$ Often
$\square$ Sometimes
$\square$ Seldom
$\square$ Never

$61 \%$ 
Figure 5: How Often Do You Eat the Food from Your Country of Origin?

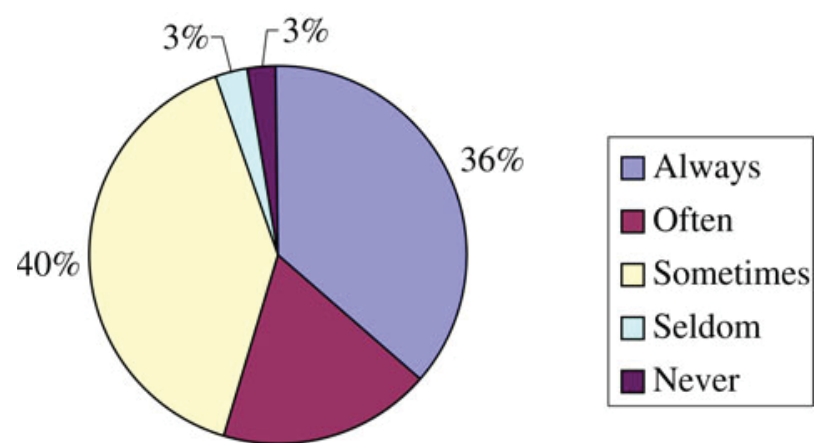

$18 \%$

This brief survey about food shows that the African population of Guangzhou, while still embedded in its traditional African food culture, is also open to trying out Chinese cuisine. Perhaps surprisingly, there exists a large number of African restaurants of all kinds of quality in the buildings in which sizeable proportions of Africans are found, far more than in Hong Kong, and these are patronized not only by Africans but also by Chinese and others. Indeed some Chinese people are beginning to learn how to make African food. But Africans can also be seen in many Chinese restaurants. For mixed couples, it is often the case that the Chinese wife and the African husband take turns in preparing Chinese and African food. Food habits give one of the clearest indications that the African community in Guangzhou is serving as a cultural bridge between African and Chinese societies.

To complete this section on constructing a socio-cultural profile of Africans in Guangzhou, we draw from our in-depth interviews of members of this community. Of the eight interviews, two are described here, one with an African trader and one with a Chinese shop assistant who interacts with Africans.

Mr A, a Malian, started his business in Tianxiu building in 2000 as a salesman. He bought garments and other goods in Guangzhou and sold them at a higher price in Mali. This is a typical way for an African to start a business, and Guangzhou is a good place to buy products at a low price. After accumulating more capital and familiarizing himself with Guangzhou, Mr A set up an office in Tianxiu building block A five years ago and started his trading business. As a trader, he first receives orders and money from Africa, and then purchases and ships the goods to his customers. He sends goods to different parts of Africa - Congo, Zambia, Ivory Coast, Benin and, of course, Mali. Trading companies like Mr A's mean that an African businessman in Africa does not always need to come to Guangzhou in person to purchase products. Even so, many African businessmen do choose to come and explore more business opportunities and to select goods by themselves.

Since Mr A set up his office, he has stayed in Guangzhou. For Mr A, life is not difficult. In his opinion, life in Guangzhou is not too different from life in his 
home country. He can enjoy African food and has his African friends. However, communication has always been a problem for him. This is mainly because not many people in Guangzhou speak English. However, he can now speak a little Chinese so he does not have so much of a problem and can communicate and interact with his Chinese hosts.

Like many African businessmen, Mr A complains a lot about visa problems. Indeed, as a direct result of such problems he plans to go back to Mali this year. African businessmen in Guangzhou were very unhappy about the tightening of visa restrictions in the run-up to the Beijing Olympics in August 2008, which greatly affects their business activities. ${ }^{20}$

The second interview is with Ms Li, who is from Lanzhou, the capital of Gansu province in north-western China. She works in Guangzhou as a shop assistant in a casual wear shop in Canaan Export Clothes Market. As this market mainly targets Africans, Ms Li meets this group of customers every day. She says that a majority of the customers are from Ghana and Nigeria. Most of them are avid wholesalers and retailers.

Before working in this shop, Ms Li dealt with Chinese customers in a similar type of shop. When asked the difference between doing business with Chinese and Africans, she complains about the Africans. First, she mentions that many African customers do not keep their promises. For example, they may request the company to supply them with goods within a week but they do not come and collect them on time. Secondly, after goods have been produced for them, they may say they do not have the money. According to her, some Christian Africans handle things "in the name of God." In addition, she finds it hard to get along with African customers. This is because, to $\mathrm{Ms} \mathrm{Li}$, the Africans are too direct when meeting someone of the opposite sex. She recounted her experience of being asked by African customers to give them her phone number and address when they had only just met her. Some even declare love for her on a very first meeting, behaviour she can hardly bear as a Chinese. Hence the problems she encounters in dealing with her African customers are mostly a result of cultural and religious differences between Chinese and Africans.

These two interviews feature a member from each side of the bridge. Although they recount problems, both interviewees illustrate and confirm the bridge theory. Mr A can now communicate with his Chinese hosts after learning Chinese, and $\mathrm{Ms} \mathrm{Li}$, despite her reservations about African young men making advances to her, considers her hosts to be avid businessmen. The bridge theory does not claim that people on either side learn only positive things from each other's culture. Indeed, they can also learn to avoid negative aspects of the other culture.

This section has given a socio-cultural profile of the African community in Guangzhou. This is basically a community in the early processes of establishment. As a result it is still very much an African community steeped in 
African culture in terms of how people identify themselves, what friends they choose, what cultural activities they engage in and what they eat. However, their worldview is also changing by the day. They are gradually getting influenced by the Chinese society in which they live, and they in turn are gradually influencing the Chinese as they interact with them. Our target migrant community, whether or not it is an ethnic enclave, an outpost or integrated into its host Guangzhou community, is gradually laying cultural bridges between its source and host communities. It is becoming a solid bridge for socio-cultural relations between Africa and China.

\section{Socio-economic roles: African contributions}

The last two sections constructed sociolinguistic and socio-cultural profiles of the African community of Guangzhou and then indicated how this community is seen as laying a strong foundation for sociolinguistic contacts and socio-cultural connections between Africa and China.

This section deals with how this African community in Guangzhou is contributing to the economy and other aspects of Guangzhou life and thus performing a role as an interface between Africa and China in terms of socio-economic relations. The evidence was mainly gathered from an intensive focus group meeting with leaders of the African community. On 30 May 2008, the author and his two assistants met four African community leaders from Ghana, Guinea, Nigeria and Cameroon. ${ }^{21}$ We had an in-depth discussion about the socio-economic contributions of Africans in Guangzhou, and the leaders identified four major areas of contribution: building economic bridges between host and source community; as image builders for Africa; the creation of employment for local Guangzhou people and Chinese from other provinces; and acting as mentors to the young Chinese who work with them.

The African leaders recognized clearly that they acted as facilitators for promoting business relations between their African customers and their Chinese suppliers. As the Guinean leader pointedly indicated: "Chinese [leaders] think that Africans can do business in China without being in China and this is an error. 90 per cent of Africans in Guangzhou act as some kind of intermediary between the local businessmen in Africa and the Chinese factory, the Chinese businessmen there. Without Africans in China there is no business between Africa and China." This was one of the clearest statements as evidence in support of our theoretical argument about Africans in Guangzhou acting as bridges for business connections between Africans and Chinese.

One aspect that the leaders repeatedly complained about was the negative image of Africa and Africans in Guangzhou. These leaders saw themselves fighting for positive images of Africa. In many ways they saw themselves as the faces

21 The author thanks Dr Li Zhigang of Sun Yat-sen University for coming to this meeting and participating in our deliberations. 
of Africa, ambassadors of their source continent and culture. The Guinean leader lamented the image of Africa thus: "From the media, African people are portrayed as people dying of AIDS, people dying of hunger and starvation." The Ghanaian leader contended that the way that Africans in Guangzhou can help the Chinese to understand Africa is to provide "first-hand knowledge," a kind of direct experience of the continent and of African culture. In other words, rather than merely fighting a negative image, Africans in Guangzhou can actually provide positive examples through the way they live and interact with their Chinese hosts. Indeed, many of these leaders and their communities have tried to organize cultural events to give Guangzhou residents an opportunity to appreciate African culture, values and ways of living.

On many occasions in our focus group meeting, all four African leaders pointed to the fact that African shop owners were indeed contributing a lot to Guangzhou and China in employing a large number of Chinese people. According to the Cameroonian leader, "many Cameroonian businessmen who own their own shops in China employ many Chinese people." For him "many Chinese people who speak English and French do so not because they learnt it very well at school but because they work with Africans."

A surprising factor about the African contribution in Guangzhou that is least noticed and which the leaders were at pains to stress is the fact that they act as mentors to many of the assistants they employ. The Ghanaian leader thinks that his office is "like another classroom" for the Chinese people who work with him. The importance of this socio-economic role performed by the African community can be best appreciated if one understands that a very large proportion of the Guangzhou workforce, especially those who work for the Africans, are migrant workers themselves who left their homes at relatively young ages to live and work alone in Guangzhou. For most of them this is the first time they have left home. It is thus not surprising that they see their African bosses and other well-respected members of the African community as mentors and educators.

\section{Discussions and Conclusion}

In an age of globalization, migrant communities are becoming more and more salient, especially in major cities of the world. People never migrate empty handed. They always have at least their source cultures and native languages with them. In addition, members of migrant communities also gradually learn the cultures, languages and value systems of their host community. Migrant communities as contact points between different cultures and languages therefore serve as attractive study entities for many interdisciplinary areas such as contact linguistics, sociolinguistics, urban anthropology and cross-cultural communication studies.

The African trading community of Guangzhou is one such migrant community that deserves attention. This article has presented some of the results of an 
extensive questionnaire survey and interviews of people in this emerging community. The main objectives of the study have been to provide a description of the demographic and sociolinguistic composition of this community; to outline the socio-economic role that these community members are playing in Guangzhou; and, based on these facts, to argue that the community, because of its composition and role, provides vital links and connections between Africa and China.

To achieve these objectives, we have, first, compiled profiles of this community based on our field study and on our own experience as participant-observers. Secondly, we have proposed a bridge theory to explicate the relationship between the migrant community and its source community on the one hand, and its host community on the other. The "migrant community as bridge" theory can be the basis for analysing many interface issues in disciplines such as contact linguistics and cross-cultural anthropology. Already we are seeing many cross-cultural communication issues arising, such as the phenomenon of "calculator communication" described above.

To conclude, there are consequences for such a view of the African community in Guangzhou. If the community serves as a contact point, a bridge between Africa and China, it follows that one of the best ways to promote AfricaChina economic relations is for the Guangzhou metropolitan authorities, the Guangdong provincial government and indeed the Chinese state as a whole to recognize this important role that the community is playing, take advantage of it and use it to strengthen Africa-China relations on many fronts, including linguistic, cultural and economic. It is important that the Chinese government enacts more business-friendly immigration policies to smoothen travel to and residence in China. Many Africans in Guangzhou and other parts of China report of how draconian and corrupt the police and some other law enforcement officers are. They can allegedly arrest an illegal immigrant, take money from him and release him, only to re-arrest him a little way down the street to demand more bribes. The central government ought to investigate such serious allegations and punish the local authority personnel responsible.

Both the Chinese government on the one hand and the African governments on the other could harness the important roles played by the community, and address the challenges it is facing - such as unrealistic visa and residency restrictions, and generally unclear paths to permanent residency and citizenship - to enhance the growing economic relations between Africa and China. The African trading community in Guangzhou serves as a salient emerging bridge between Africa and China that cannot continue to be ignored in efforts to develop effective socio-economic relations between Africa and China. 